\title{
Deletion of a Chromosome Arm Altered Wheat Resistance to Fusarium Head Blight and Deoxynivalenol Accumulation in Chinese Spring
}

\author{
Hong-Xiang Ma, Jiangsu Academy of Agricultural Sciences, Nanjing 210014, China, and Department of Agronomy, \\ Kansas State University, Manhattan 66506; Gui-Hua Bai, Unites States Department of Agriculture-Agricultural \\ Research Service-Plant Science and Entomology Research Unit; Bikram S. Gill, Department of Plant Pathology, \\ Kansas State University, Manhattan 66506; and L. Patrick Hart, Department of Plant Pathology, Michigan State \\ University, East Lansing 48824
}

\begin{abstract}
Ma, H.-X., Bai, G.-H., Gill, B. S., and Hart, L. P. 2006. Deletion of a chromosome arm altered wheat resistance to Fusarium head blight and deoxynivalenol accumulation in Chinese Spring. Plant Dis. 90:1545-1549.

Fusarium head blight (FHB), caused by Fusarium graminearum Schwabe, is an important disease of wheat worldwide. Production of deoxynivalenol (DON) in infected wheat grain by $F$. graminearum is a major safety concern when considering use of the grain as feed for livestock or for human consumption. Determining chromosome locations of FHB-related genes may facilitate enhancement of wheat resistance to FHB and DON accumulation. In this study, a set of 30 ditelosomic lines derived from Chinese Spring, a moderately FHB-resistant landrace from China, were evaluated for proportion of scabbed spikelets per inoculated spike in the greenhouse and for DON contamination in harvested grain over 2 years. Significant variation in the proportion of scabbed spikelets was observed among ditelosomic lines, ranging from 13 to $95 \%$. Seven ditelosomic lines exhibited a greater proportion of scabbed spikelets and three of these also had greater DON content than Chinese Spring $(P=0.01)$, suggesting that those missing chromosome arms may carry genes that contribute to resistance to FHB. Six ditelosomic lines had a reduction in proportion of scabbed spikelets, suggesting that susceptibility factors or resistance suppressors may be on these missing chromosomal arms. Selection for low proportion of scabbed spikelets in general will select for low DON content.
\end{abstract}

Fusarium head blight (FHB), also called head scab, mainly caused by Fusarium graminearum Schwabe (teleomorph = Gibberella zeae (Schwein.) Petch), is a devastating wheat disease in warm and humid wheat-growing areas in the world (4). Infected spikes produce shriveled kernels that result in low yield. Quality losses in infected grains are due mainly to damage in protein structure and contamination with deoxynivalenol (DON), a mycotoxin produced by the pathogen during infection (33-35). DON in harvested grain is becoming a major health concern when the

\section{Corresponding author: G.-H. Bai \\ E-mail: gbai@ksu.edu}

Any opinions, findings, conclusions, or recommendations expressed in this publication are those of the authors and do not necessarily reflect the view of the United States Department of Agriculture.

This is contribution No. 06-111-5 of the Kansas Agricultural Experiment Station, Manhattan, KS.

Accepted for publication 25 August 2006.

\section{DOI: 10.1094/PD-90-1545}

This article is in the public domain and not copyrightable. It may be freely reprinted with customary crediting of the source. The American Phytopathological Society, 2006. grain is to be used for human consumption or as animal feed (18).

Chemical and agronomic control measures are either only moderately effective or unfeasible. The use of FHB-resistant cultivars is still one of the most effective methods to reduce losses caused by FHB (26). Wheat cultivars with highly effective FHB resistance have been reported from several countries $(3,8,14,20,32)$. A major quantitative trait locus (QTL) for FHB resistance on chromosome 3BS of Sumai 3 has been shown to be stable across various genetic backgrounds and environments (4). Many other QTLs have been reported, but their chromosome locations are inconsistent among studies (4).

'Chinese Spring,' a landrace from China (28), has shown moderate resistance to FHB in field conditions. Aneuploid genetic stocks are useful tools for studying the genetic effects of individual chromosomes or chromosome arms on various traits. Ditelosomic lines of Chinese Spring have been used to study aluminum tolerance $(2,25)$, grain protein content $(6)$, and acquired thermo-tolerance (24), and to locate the genes related to those characters on various chromosomes. In this study, a set of ditelosomic lines from Chinese Spring was used to determine the effect of individual chromosome arms on FHB infection and DON accumulation.

\section{MATERIALS AND METHODS}

Plant materials. Chinese Spring and its 30 ditelosomic lines were evaluated for FHB symptom spread within a spike (type II resistance) in a greenhouse at Kansas State University in 2003 and 2004. Wheat cvs. Sumai 3 and Clark were used as resistant and susceptible controls, respectively. Wheat seedlings were planted in a growth chamber for vernalization at $4^{\circ} \mathrm{C}$ for 4 weeks before being transplanted to pots on greenhouse benches. Greenhouse temperatures averaged $25^{\circ} \mathrm{C}$, with a range of 19 to $30^{\circ} \mathrm{C}$ during the day; and $19^{\circ} \mathrm{C}$, with a range of 17 to $21^{\circ} \mathrm{C}$ at night.

FHB evaluation. The inoculum of $F$. graminearum was obtained from a field isolate (GZ 3639) in Kansas and has been well characterized for its strong virulence and high DON content in harvested grain (11). Mung bean liquid medium was used to produce the conidia for inoculation (3). A hypodermic syringe was used to inject a droplet of conidia (approximately 1,000 spores) into a central floret of selected spikes at anthesis. The inoculated plants were misted with tap water from a misting nozzle installed inside an inoculation chamber that consisted of a polyethylenesheet-covered frame on a greenhouse bench. Temperatures within the moist chamber were 23 to $25^{\circ} \mathrm{C}$ and relative humidity was $100 \%$. On the fourth day after inoculation, plants were returned to their original positions on greenhouse benches.

Disease severity was calculated as the proportion of scabbed spikelets per inoculated spike at 21 days after inoculation. For comparison of FHB severity among Chinese Spring ditelosomic lines and the controls, area under the disease progress curve (AUDPC) and thousand-seed weight also were evaluated. AUDPC was calculated from the proportion of scabbed spikelets per inoculated spike at 7, 14, and 21 days after inoculation according to Shaner and Finney (29) as follows:

$$
\text { AUDPC }=\sum_{i j}^{n}\left[\left(Y_{i+1}+Y_{i}\right) / 2\right]\left(t_{i+1}-t_{i}\right)
$$

where $Y_{i}$ is the proportion of scabbed spikelets per inoculated spike at the $i$ th observation, $t_{i}$ is time (days) at the $i$ th observation, and $n$ is total number of observations. 
Harvested spikes from each pot were threshed separately by hand and carefully cleaned to assure that all shriveled kernels were collected. Seeds were counted and weighed. The greenhouse test was conducted in a randomized complete block design with three replications. Each replication had five inoculated plants. Visual FHB symptoms on each spike were rated individually. Thousand-seed weight was calculated based on bulked seed harvested from the inoculated spikes in each of three pots. The experiment was repeated once.

DON and data analysis. The kernels harvested from inoculated spikes of each line were bulked for DON analysis. DON content in a wheat sample was analyzed by the enzyme-linked immunosorbent assay (ELISA) at Michigan State University (16). Analysis of variances for DON and the proportion of scabbed spikelets were conducted using the SAS program (v8.0; SAS Institute, Cary, NC). FHB severity was analyzed using data from each experiment and combined data over both experiments; whereas DON data were analyzed using only combined data from two experiments. Significant differences between treatment means were declared at $P<0.01$ using the least significant difference (LSD) method. Correlations also were calculated among the measured variables.

\section{RESULTS}

FHB infection in Chinese Spring. In two greenhouse tests, FHB symptoms appeared as early as 4 days after inoculation and increased at different rates among Chinese Spring, Sumai 3, and Clark. At 21 days after inoculation, mean proportion of scabbed spikelets per inoculated spike and AUDPC in both experiments were lowest for resistant cv. Sumai 3, highest for Clark, and intermediate for Chinese Spring (Table 1). DON content among cultivars was positively correlated with proportion of scabbed spikelets $(r=0.97, n=9, P<0.001)$ and AUDPC $(r=0.99, n=9, P<0.001)$. Thousand-seed weight was negatively correlated with proportion of scabbed spikelets $(r=$ $-0.98, n=9, P<0.001)$, AUDPC $(r=$ $-0.97, n=9, P<0.001)$, and DON content $(r=-0.98, n=9, P<0.001)$.

FHB reactions of ditelosomic lines of Chinese Spring. Significant variation in proportion of scabbed spikelets was ob- served among ditelosomic lines of Chinese Spring and between experiments (Tables 2 and 3). This result indicates that these ditelosomic lines differ in their reactions to FHB, and that environments also affect the expression of the FHB resistance in the ditelosomic lines. The proportion of scabbed spikelets varied from 13.0 to $95.0 \%$ among the ditelosomic lines, whereas the proportion of scabbed spikelets of Chinese Spring was 50.7\% (Table 3). Nine ditelosomic lines (DT1AS, DT2AS, DT3AS, DT1BL, DT3BL, DT6BL, DT7BS, DT1DL, and DT1DS) had a greater proportion of scabbed spikelets than Chinese Spring over both experiments $(P<0.05)$. The differences in proportions of scabbed spikelets between Chinese Spring and ditelosomic lines DT1AS, DT2AS, DT3AS, DT3BL, DT6BL, DT1DL, and DT1DS were highly significant $(P<0.01)$ over two experiments. When Chinese Spring was lacking one of the chromosome arms 1AL, 2AL, 3AL, 3BS, 6BS, 1DS, or 1DL, the derived lines had significantly greater proportion of scabbed spikelets than the original Chinese Spring. In addition, 13 other lines with one arm missing showed significantly higher FHB severity $(P<0.01)$ than Chinese Spring in 2004 experiment, but the mean over two experiments was not significant $(P<0.01)$ due to either similar FHB severity as Chinese Spring or lower severity than Chinese Spring in 2003 (Table 3). In contrast, five different ditelosomic lines (DT7AL, DT3BS, DT6BS, DT7BL, and DT4DL) had a significantly lower proportion of scabbed spikelets compared with Chinese Spring for both individual experiments and for mean FHB severity over two experiments $(P<0.01)$. Line DT6AL also was significantly different from Chinese Spring in both individual experiments, although its mean over two experiments was not significant.

DON was detected in the kernels of all ditelosomic lines, ranging from 0.6 to 93.5 $\mathrm{mg} / \mathrm{kg}$, whereas the DON content in Chinese Spring was $31.3 \mathrm{mg} / \mathrm{kg}$ (Table 3). DON content differed significantly among ditelosomic lines $(P<0.01$; Table 2$)$. Ditelosomic lines DT2AS, DT3AS, and DT1DS had significantly greater DON content than Chinese Spring, whereas DT6AL, DT7AL, DT4DL, and DT6DS had significantly lower DON content than Chinese Spring $(P<0.05)$. The lowest DON content was detected in ditelosomic line DT7AL $(0.6 \mathrm{mg} / \mathrm{kg})$, which also had the lowest proportion of scabbed spikelets among all ditelosomic lines. The highest DON content was found in DT1DS (93.5 $\mathrm{mg} / \mathrm{kg}$ ). DT1AS had the highest proportion of scabbed spikelets, with DON content of $64.3 \mathrm{mg} / \mathrm{kg}$.

Genotypic variation was significant for both proportion of scabbed spikelets and DON content (Table 2) over 2 years. The year effect on proportion of scabbed spikelets also was significant. The significant correlations of proportion of scabbed spikelets $(r=0.75)$ and DON content $(r=$ $0.79)$ were observed between 2 years $(P<$ $0.01)$. The correlation coefficients between the proportion of scabbed spikelets and DON content were also significant $(r=0.69$ in 2003 and $r=0.64$ in 2004, $P<0.01$ ).

\section{DISCUSSION}

Single-floret inoculation was employed to evaluate FHB infection in this study.

Table 2. Analysis of variance of proportion of scabbed spikelets and deoxynivalenol content for Chinese Spring ditelosomic lines evaluated using a single-floret inoculation method in two greenhouse experiments $^{\mathrm{a}}$

\begin{tabular}{|c|c|c|c|c|}
\hline Source of variance & SS & df & MS & $\boldsymbol{F}$ \\
\hline \multicolumn{5}{|c|}{ Proportion of scabbed spikelets } \\
\hline Genotype & $103,940.60$ & 30 & $3,464.69$ & $9.13^{* *}$ \\
\hline Experiment & $22,645.67$ & 1 & $22,645.67$ & $59.68 * *$ \\
\hline Genotype $\times$ experiment & $14,806.78$ & 30 & 493.56 & 1.30 \\
\hline Error & $47,048.94$ & 124 & 379.43 & $\cdots$ \\
\hline \multicolumn{5}{|l|}{ Deoxynivalenol content } \\
\hline Genotype & $41,496.62$ & 30 & $1,383.22$ & $8.50 * *$ \\
\hline Experiment & 222.55 & 1 & 222.55 & 1.37 \\
\hline Error & $4,881.59$ & 30 & 162.72 & $\ldots$ \\
\hline
\end{tabular}

a $\mathrm{SS}=$ sum of squares, MS = mean square, and $* *$ indicates significant $F$ value at $P<0.01$.

Table 1. Proportion of scabbed spikelets (PSS) at 21 days after inoculation, area under disease progress curve (AUDPC), thousand-seed weight (TSW), and deoxynivalenol (DON) content of Chinese Spring, Sumai 3, and Clark

\begin{tabular}{|c|c|c|c|c|c|c|c|c|}
\hline \multirow[b]{2}{*}{ Cultivar $^{\mathrm{a}}$} & \multicolumn{4}{|c|}{2003} & \multicolumn{4}{|c|}{2004} \\
\hline & PSS (\%) & AUDPC & TSW (g) & DON (mg/kg) & PSS (\%) & AUDPC & TSW (g) & DON (mg/kg) \\
\hline Chinese Spring & 47.6 & 4.3 & 21.9 & 27.5 & 53.8 & 4.5 & 22.7 & 35.0 \\
\hline Sumai 3 & 7.8 & 1.4 & 29.2 & 0.5 & 11.8 & 1.5 & 30.4 & 0.6 \\
\hline Clark & 94.0 & 8.9 & 8.1 & 106.6 & 99.6 & 10.9 & 10.14 & 125.0 \\
\hline $\mathrm{LSD}_{0.05}$ & 13.7 & 1.3 & 5.7 & 25.1 & 9.3 & 2.5 & 3.6 & 26.4 \\
\hline $\mathrm{LSD}_{0.01}$ & 24.2 & 2.3 & 8.9 & 43.2 & 16.4 & 4.4 & 6.4 & 45.3 \\
\hline
\end{tabular}

${ }^{a} \operatorname{LSD}_{0.05}$ and $\mathrm{LSD}_{0.01}=$ least significant difference at $P<0.05$ or 0.01 , respectively. 
This method has been accepted as a standard inoculation method for measuring wheat resistance to spread of FHB symptoms within a spike (type II resistance; 27). Type II resistance has been considered to be a more stable type of resistance compared with resistance to initial infection (5). In this study, wheat cv. Chinese Spring was shown to be moderately resistant to FHB compared with the well-known resistant cv. Sumai 3 and highly susceptible cv. Clark on the basis of proportion of scabbed spikelets per inoculated spike, AUDPC, and DON content over two experiments. These results agree with a previous report by Grausgruber et al. (15).

The genetic effect of different chromosome arms on FHB resistance can be characterized simultaneously in the same genetic background using ditelosomic lines $(2,6,24,25)$. Significant differences in type II resistance and DON content compared with Chinese Spring were observed in many of the ditelosomic lines derived from Chinese Spring in this study. Our result suggested that seven chromosome arms of Chinese Spring most likely carry genetic factors for enhancement of type II resistance and most of those chromosome arms associated with a low proportion of scabbed spikelets also were reported previously through QTL mapping of different cultivars $(1,7,9,10,13,15,31,36,40)$. Grausgruber et al. (15) reported that chromo- somes $3 \mathrm{~B}$ and 5A might enhance resistance to $F$. culmorum in Chinese Spring after they had observed that substitution of some Chinese Spring chromosomes with corresponding chromosomes from a susceptible cultivar lead to disease increase. QTLs also were reported on 2AL $(1,13)$, 3AL $(1,13)$, 3BS $(1,7,9,10)$, 6BS $(31,40)$, and 1DL (36) from different cultivars. The QTL on 3BS was detected in Sumai 3 and its derivatives $(1,40)$, Chinese landraces Wangshuibai (17,38,41), Ning 894037 (31), and Renan (13). Other QTLs mainly were QTLs with minor effects on FHB resistance. In this study, removal of some critical chromosome arms caused significant increase in the proportion of scabbed spikelets. Lines DT1AS, DT2AS, DT3BL, and DT1DL had about 34 and 46\% higher proportion of scabbed spikelets in 2003 and 2004, respectively, than Chinese Spring. This result indicates that the genetic factor or factors on these missing chromosome arms independently can make a cultivar moderately resistant to completely susceptible, assuming that the dosage effect of the genetic factors on the opposite arm of the same chromosome was negligible. Therefore, all those chromosome arms seem to have genetic factors with a major effect on type II resistance in the Chinese Spring background, which is different from other studies. The discrepancy between results from this study and others could be due to different sources of resistance, dosage effect of gene on the opposite arm of the chromosome because it was doubled, and possible interaction between genes on different chromosomes that was not considered in this study.

In contrast, six ditelosomic lines (DT7AL, DT3BS, DT6BS, DT7BL, DT4DL, and DT6AL) had a significantly lower proportion of scabbed spikelets per inoculated spike than Chinese Spring, which suggests that those missing chromosome arms may carry a possible susceptibility factor or factors or resistance suppressors. FHB susceptibility factors have not received much attention to date. Yao et al. (37) reported that the Chinese Spring and Sumai 3 chromosome 2D substitution line was more susceptible than Chinese Spring and speculated that the susceptibility genetic factors on chromosome $2 \mathrm{D}$ of Sumai 3 might be responsible for the increased FHB severity. Zhou et al. (39) tested the same substitution lines and reported that chromosomes $2 \mathrm{~B}, 2 \mathrm{D}$, and $4 \mathrm{D}$ from Sumai 3 increased DON content. In many mapping efforts $(1,13,17,30)$, researchers usually were interested in identification of resistance genes, not susceptibility factors. If a susceptibility factor is identified in a resistant parent, it usually is interpreted as the susceptible parent contributing the resistance gene (1). However, resistance and susceptibility are opposite

Table 3. Proportion of scabbed spikelets (PSS) and deoxynivalenol (DON) contents for ditelosomic lines and their euploid parent of Chinese Spring ${ }^{\mathrm{a}}$

\begin{tabular}{|c|c|c|c|c|c|c|c|}
\hline \multirow[b]{2}{*}{ Line name } & \multirow[b]{2}{*}{ Missing chromosome arm } & \multicolumn{3}{|c|}{ PSS $(\%)$} & \multicolumn{3}{|c|}{ DON content $(\mathrm{mg} / \mathrm{kg})$} \\
\hline & & 2003 & 2004 & Mean & 2003 & 2004 & Mean \\
\hline DT1AS & $1 \mathrm{AL}$ & $90.0 * *$ & $100.0 * *$ & $95.0 * *$ & 55.3 & 73.3 & $64.3 *$ \\
\hline DT1DL & $1 \mathrm{DS}$ & $92.3 * *$ & $93.8 * *$ & $93.1 * *$ & 37.2 & 46.0 & 41.6 \\
\hline DT2AS & $2 \mathrm{AL}$ & $83.8 * *$ & $100.0 * *$ & $91.9 * *$ & 86.0 & 88.0 & $87.0^{* *}$ \\
\hline DT3BL & $3 B S$ & $84.6^{* *}$ & $94.6 * *$ & $89.6^{* *}$ & 50.4 & 70.8 & $60.6^{*}$ \\
\hline DT1DS & $1 \mathrm{DL}$ & $70.8 *$ & $93.1 * *$ & $81.9 * *$ & 90.0 & 96.9 & $93.5^{* *}$ \\
\hline DT3AS & $3 \mathrm{AL}$ & $73.7 * *$ & $84.3 * *$ & $79.0 * *$ & 80.0 & 92.2 & $86.1^{* *}$ \\
\hline DT6BL & $6 \mathrm{BS}$ & $75.2 * *$ & $79.3 * *$ & $77.3 * *$ & 38.7 & 44.7 & 41.7 \\
\hline DT1BL & $1 \mathrm{BS}$ & $71.0^{*}$ & $80.4 * *$ & $75.7 *$ & 50.0 & 65.4 & $57.7 *$ \\
\hline DT7BS & $7 \mathrm{BL}$ & 68.0 & $79.6^{* *}$ & $73.8^{*}$ & 10.0 & 13.0 & 11.5 \\
\hline DT7DL & 7DS & $69.7 *$ & $76.1 * *$ & 72.9 & 31.2 & 26.2 & 28.7 \\
\hline DT1AL & $1 \mathrm{AS}$ & 58.3 & $79.6 * *$ & 68.9 & 41.0 & 29.9 & 35.4 \\
\hline DT3AL & $3 \mathrm{AS}$ & $36.9^{*}$ & $93.6 * *$ & 65.3 & 29.7 & 50.4 & 40.4 \\
\hline DT4BS & $4 \mathrm{BL}$ & 55.6 & $63.7 *$ & 59.6 & 11.4 & 12.2 & 11.8 \\
\hline DT6AS & $6 \mathrm{AL}$ & 41.1 & $77.5^{* *}$ & 59.3 & 6.25 & 32.5 & 34.4 \\
\hline DT5DL & $5 \mathrm{DS}$ & 42.8 & $75.5 * *$ & 59.1 & 20.0 & 24.5 & 22.3 \\
\hline DT2DL & $2 \mathrm{DS}$ & 43.5 & $69.9 * *$ & 56.7 & 20.1 & 29.9 & 25.0 \\
\hline DT1BS & $1 \mathrm{BL}$ & $40.0 *$ & $71.5 * *$ & 55.7 & 17.6 & 15.5 & 16.6 \\
\hline Chinese Spring & None & 53.4 & 48.0 & 50.7 & 28.3 & 34.3 & 31.3 \\
\hline DT5AL & $5 \mathrm{AS}$ & $35.8^{*}$ & $65.2 * *$ & 50.5 & 14.0 & 5.6 & 9.8 \\
\hline DT7AS & 7AL & $33.6 * *$ & $65.0 * *$ & 49.3 & 17.0 & 7.3 & 12.2 \\
\hline DT5BL & $5 \mathrm{BS}$ & $37.0 *$ & $60.8^{*}$ & 48.9 & 9.75 & 16.7 & 13.2 \\
\hline DT4DS & $4 \mathrm{DL}$ & $32.0 * *$ & $63.4 *$ & 47.7 & 4.57 & 10.0 & 7.3 \\
\hline DT6DL & $6 \mathrm{DS}$ & $26.8 * *$ & $65.3 * *$ & 46.0 & 29.8 & 29.8 & 29.8 \\
\hline DT4AL & $4 \mathrm{AS}$ & $8.1 * *$ & $65.0 * *$ & 36.6 & 11.6 & 7.4 & 9.5 \\
\hline DT6AL & $6 \mathrm{AS}$ & $27.8 * *$ & $31.0 * *$ & 29.4 & 1.9 & 5.2 & $3.5^{*}$ \\
\hline DT6DS & $6 \mathrm{DL}$ & $36.7 *$ & $17.8 * *$ & $27.2^{*}$ & 2.5 & 4.6 & $3.6^{*}$ \\
\hline DT6BS & $6 \mathrm{BL}$ & $21.1 * *$ & $28.1 * *$ & $24.6^{* *}$ & 20.4 & 30.4 & 25.4 \\
\hline DT4DL & 4DS & $10.4 * *$ & $30.6 * *$ & $20.5 * *$ & 2.9 & 2.9 & $2.9^{*}$ \\
\hline DT7BL & $7 \mathrm{BS}$ & $21.8 * *$ & $18.7 * *$ & $20.3 * *$ & 4.6 & 7.7 & 6.2 \\
\hline DT3BS & $3 B L$ & $17.6^{* *}$ & $17.6^{* *}$ & $17.6^{* *}$ & 10.2 & 3.1 & 6.7 \\
\hline DT7AL & 7AS & $13.3 * *$ & $12.8 * *$ & $13.0 * *$ & 0.6 & 0.6 & $0.6^{*}$ \\
\hline $\mathrm{LSD}_{0.05}$ & $\ldots$ & 13.4 & 12.4 & 22.3 & $\ldots$ & 26.0 & $\ldots$ \\
\hline $\mathrm{LSD}_{0.01}$ & $\ldots$ & 17.8 & 16.5 & 25.4 & $\ldots$ & 40.4 & $\ldots$ \\
\hline
\end{tabular}

${ }^{a}$ In PSS and DON content, * and ** are significantly different from Chinese Spring at $P<0.05$ and 0.01 , respectively. LSD $=$ least significant difference. 
ends of the same spectrum, and resistance is relative to susceptibility (23). Research has greatly increased our knowledge on the genetic mechanisms of plant resistance to diseases. Garvin et al. (12) reported that durum line LDN (DIC-2A), in which the chromosome $2 \mathrm{~A}$ of durum cv. Langdon was replaced by the corresponding one from a wild emmer line 'Israel A' (DIC), showed an increase in FHB susceptibility compared with Langdon. Preliminary mapping work indicated that at least one region of chromosome $2 \mathrm{~A}$ from Israel $\mathrm{A}$ was associated with increased susceptibility to FHB. This chromosome also was found to suppress the action of a major FHB resistance QTL on chromosome 3A from Israel A (12). In the current study, removal of one individual chromosome arm of some chromosomes caused an average $29.0 \%$ reduction in proportion of scabbed spikelets. This result suggests that the genetic factors on those individual chromosomes or chromosome arms independently can make a cultivar moderately resistant to highly resistant. One example is that a high level of resistance was achieved by substitution of Chinese Spring chromosome 7A with a corresponding chromosome from Sumai 3 (37,39). This line showed the same resistance as Sumai 3. Mapping results indicated that Sumai 3 did not have any QTLs for FHB resistance on chromosome 7A $(1,9,10,19)$. Therefore, the Chinese Spring chromosome 7A likely contains susceptible genetic factors with a major effect. The increased resistance was due to loss of either susceptibility factors or resistance suppressors on Chinese Spring chromosome 7A, not due to addition of resistance factors from Sumai 3. Results of this study indicate that resistance could be increased by removal of chromosome arm 7AS of Chinese Spring because DT7AL showed a very low proportion of scabbed spikelets $(13.0 \%)$. The results from this study suggest that a moderately resistant cultivar may carry several genetic factors for both resistance and susceptibility. A resistant cultivar may be developed by adding resistant genetic factors, eliminating susceptibility factors, or both. Removal of susceptibility factors to improve cultivar resistance may be a useful alternative for wheat FHB improvement. In breeding programs, transfer of resistance genes from highly resistant germplasm into commercial cultivars by crossing between highly resistant and highly susceptible parents usually leads to selected lines with some undesired agronomic traits due to so many undesirable agronomic traits in the resistant parent. In fact, some wheat cultivars used for commercial production in FHB epidemic regions are moderately resistant or moderately susceptible to FHB and have similar FHB resistance to that of Chinese Spring. If susceptibility factors can be identified in these cultivars and eliminated by crossing between moder- ately resistant and moderately susceptible parents, it may be easier to develop new cultivars with acceptable levels of resistance and other desirable agronomic traits than it is through crosses between highly resistant and susceptible parents. Therefore, more research is needed on susceptibility factors in commercial cultivars that are moderately resistant or moderately susceptible, and to investigate their effects on FHB infection.

The relationship between FHB severity and DON content is still inconclusive. Bai et al. (3) found significant correlation between FHB symptom rating and DON content, and proposed that the percentage of scabbed spikelets generally could be used to predict DON content in harvested wheat grain. Miller et al. (21) and Mirocha et al. (22) also reported that resistant cultivars had lower DON content than did susceptible cultivars. In the current study, several chromosome arms were associated with significantly higher or lower DON content than Chinese Spring. A high proportion of scabbed spikelets was correlated with high DON content. Significant correlation between scabbed spikelets and DON content suggests that this low DON content could be merely due to lower disease because of the Type II resistance. Several lines with a significantly different proportion of scabbed spikelets did not differ in DON content from that of Chinese Spring. This may be due to the nongenetic variation for DON content or evaluation that was much larger than that for the proportion of scabbed spikelets.

\section{ACKNOWLEDGMENTS}

This research is partially funded by the United States Wheat and Barley Scab Initiative and the International cooperative project (2004DFA01100) of China.

\section{LITERATURE CITED}

1. Anderson, J. A., Stack, R. W., Liu, S., Waldron, B. L., Fjeld, A. D., Coyne, C., MorenoSevilla, B., Mitchell, F J., Song, Q.-J., Cregan, P. B., and Frohberg, R. C. 2001. DNA markers for Fusarium head blight resistance QTLs in two wheat populations. Theor. Appl. Genet. 102:1164-1168.

2. Aniol, A. 1990. Genetics of tolerance to aluminum in wheat (Triticum aestivum L. Thell). Plant Soil 123:223-227.

3. Bai, G. H., Plattner, R., Desjardins, A., and Kolb, F. L. 2001. Resistance to Fusarium head blight and deoxynivalenol accumulation in wheat. Plant Breed. 120(1):1-6.

4. Bai G. H., and Shaner, G. E. 2004. Management and resistance in wheat and barley to Fusarium head blight. Annu. Rev. Phytopathol. 42:135-161.

5. Bai, G. H., Shaner, G. E., and Ohm, H. W. 2000. Inheritance of resistance to Fusarium graminearum in wheat. Theor. Appl. Genet. 100:1-8

6. Barneix, A. J., Fatta, N., Kade, M., Pfluger, L., and Suarez, E. Y. 1998. Effect of wheat chromosome 7BS on grain protein concentration. Cereal Res. Commun. 26:101-106.

7. Bourdoncle, W., and Ohm, H. W. 2003. Quantitative trait loci for resistance to Fusarium head blight in recombinant inbred wheat lines from the cross Huapei 57-2/Patterson.
Euphytica 131:131-136.

8. Buerstmayr, H., Lemmens, M., Grausgruber, H., and Ruckenbauer, P. 1996. Scab resistance of international wheat germplasm. Cereal Res. Commun. 24:195-201.

9. Buerstmayr, H., Lemmens, M., Hartl, L. Doldi, L., Steiner, B., Stierschneider, M., and Ruckenbauer, P. 2002. Molecular mapping of QTLs for Fusarium head blight resistance in spring wheat. I. Resistance to fungal spread (type II resistance). Theor. Appl. Genet. 104:84-91.

10. Buerstmayr, H., Steiner, B., Hartl, L., Griesser, M., Angerer, N., Lengauer, D., Miedaner, T. Schneider, B., and Lemmens, M. 2003. Molecular mapping of QTLs for Fusarium head blight resistance in spring wheat. II. Resistance to fungal penetration and spread. Theor. Appl. Genet. 107:503-508.

11. Desjardins, A. E., Proctor, R. H., Bai, G. H., McCormick, S. P., Shaner, G. E., Buechley, G. and Hohn, T. M. 1996. Reduced virulence of trichothecene antibiotic-nonproducing mutants of Gibberella zeae in wheat field tests. Mol. Plant-Microbe Interact. 9:775-781.

12. Gavin, D. F., and Stack, R. W. 2004. Molecular genetics of Fusarium head blight susceptibility associated with chromosome $2 \mathrm{~A}$ from the wild emmer line "Israel A". Page 60 in: Proc. 2nd Int. Symp. Fusarium Head Blight. S. M. Canty, T. Boring, J. Wardwell, and R. W. Ward, eds. Michigan State University, East Lansing.

13. Gervais, L., Dedryver, F., Morlais, J. Y., Bodusseau, V., Negre, S., Bilous, M., Groos, C., and Trottet, M. 2003. Mapping of quantitative trait loci for field resistance to Fusarium head blight in a European winter wheat. Theor. Appl. Genet. 106:961-970.

14. Gilbert, J., and Tekauz, A. 2000. Review: recent developments in research on Fusarium head blight of wheat in Canada. Can. J. Plant Pathol. 22:1-8.

15. Grausgruber, H., Lemmens, M., Burstmayr, H. and Ruckenbauer, P. 1999. Resistance of 'Chinese Spring' substitution lines carrying chromosomes from 'Cheyenne,' 'Hope' and 'Lutescens 62' wheat to head blight caused by Fusarium culmorum. Hereditas 130:57-63.

16. Hart, L. P., Caspe, H., Schabenberger, O., and Ng, P. 1998. Comparison and enzyme-linked immunosorbent assay for deoxynivalenol in milled fractions of naturally contaminated wheat. J. Food Prod. 61:1695-1697.

17. Lin, F., Kong, Z. X., Zhu, H. L., Xue, S. L., Wu, J. Z., Tian, D. G., Wei, J. B., Zhang, C. Q. and Ma, Z. Q. 2004. Mapping QTL associated with resistance to Fusarium head blight in the Nanda2419 $\times$ Wangshuibai population. I. Type II resistance. Theor. Appl. Genet. 109:15041511

18. Luo, Y., Yoshizawa, T., and Katayama, T. 1990. Comparative study on the natural occurrence of Fusarium mycotoxins (trichothecenes and zearalenone) in corn and wheat from high- and low-risk areas for human esophageal cancer in China. Appl. Environ. Microbiol. 56:37233726.

19. Ma, H. X., Bai, G. H., Zhang, X., and Lu, W.Z. 2006. Main effects, epistasis, and environmental interactions of quantitative trait loci for Fusarium head blight resistance in a recombinant inbred population. Phytopathology 96:534-541.

20. Mesterhazy, A. 1995. Types and components of resistance to Fusarium head blight of wheat Plant Breed. 114:377-386.

21. Miller, J. D., Young, J. C., and Sampson, D. R. 1985. Deoxynivalenol and Fusarium head blight resistance in spring cereals. Phytopathol. Z. 113:359-367.

22. Mirocha, C. J., Xie, W. P., Xu, Y. C., Wilcoxson, R. D., Woodward, R. P., Etabarian, R. H., and Behele, G. 1994. Production of trichothecene mycotoxins by Fusarium graminearum 
and Fusarium culmorum on barley and wheat. Mycopathologia 128:19-23.

23. Nancy, A. E. 2002. Plant disease susceptibility genes? Plant Cell 14:1983-1986.

24. O'Mahony, P., Burke, J. J., and Oliver, M. J. 2000. Identification of acquired thermotolerance deficiency within the ditelosomic series of 'Chinese Spring' wheat. Plant Physiol. Biochem. 38:243-252.

25. Papernik, L. A., Bethea, A. S., Singleton, T. E., Magalhaes, J. V., Garvin, D. F., and Kochian, L. V. 2001. Mechanistic basis of Al sensitivity in the ditelosomic lines of Chinese Spring wheat. Planta 212:829-834.

26. Parry, D. W., Jenkinson, P., and McLeod, L. 1995. Fusarium ear blight (scab) in small grain cereals - a review. Plant Pathol. 44:207-238

27. Schroeder, H. W., and Christensen J. J. 1963. Factors affecting resistance of wheat to scab caused by Gibberella zeae. Phytopathology 53:831-838.

28. Sears, E. R., and Miller, T. E. 1985. The history of Chinese Spring wheat. Cereal Res. Commun. 13:261-263.

29. Shaner, G., and Finney, R. E. 1977. The effect of nitrogen fertilization on the expression of slow-mildewing resistance in Knox wheat. Phytopathology 67:1051-1056.

30. Shen, X. R., Ittu, M., and Ohm, H. W. 2003.
Quantitative trait loci conditioning resistance to Fusarium head blight in wheat line F201R. Crop Sci. 43:850-857.

31. Shen, X. R., Zhou, M. P., Lu, W., and Ohm, H. 2003. Detection of Fusarium head blight resistance QTL in a wheat population using bulked segregant analysis. Theor. Appl. Genet. 106:1041-1047.

32. Snijders, C. H. A. 1990. The inheritance of resistance to head blight caused by Fusarium culmorum in winter wheat. Euphytica 50:1118.

33. Wong, L. S. L., Abramson, D., Teakuz, A., Leisle, D., and McKenzie, R. I. H. 1995. Pathogenicity and mycotoxin production of Fusarium species causing head blight in wheat cultivars varying in resistance. Can. J. Plant Sci. 75:261-267.

34. Wu, G. Q., Peng, W. H., and Ye, H. Z. 1996. Changes in gliadin in wheat seeds infected by Fusarium graminearum. J. Sichuan Agric. Univ. 14:529-532.

35. Wu, Y. L., Wu, G. Q., and Ye, H. Z. 1997. Changes in protein components of wheat grain infected with $F$. graminearum. J. Sichuan Agric. Univ. 15:329-334

36. Yang, Z. P., Gilbert, J., Fekak, G.., and Somers, D. J. 2005. Genetic characterization of QTL associated with resistance to Fusarium head blight in a doubled-haploid spring wheat population. Genome 48:187-196.

37. Yao, J. B., Ge, Y. F., Wang, S. W., Yao, G. C. Zhou, C. F., and Qian, C. M. 1997. Chromosomal location of genes for scab resistance in wheat cultivar Sumai 3. Acta Agron. Sin 23:450-453.

38. Zhang, X., Zhou, M. P., Ren, L., Bai, G. H., Ma, H. X., Scholten, O. E., Guo, P. G., and Lu, W. Z. 2004. Molecular characterization of Fusarium head blight resistance from whea cultivar Wangshuibai. Euphytica 139:59-64.

39. Zhou, W. C., Kolb, F. L., Bai, G. H., Domier, L. L., and Yao, J. B. 2002. Effect of individual Sumai 3 chromosomes on resistance to scab spread within spikes and deoxynivalenol accumulation within kernels in wheat. Hereditas 137:81-89.

40. Zhou, W. C., Kolb, F. L., Bai, G. H., Shaner, G. E., and Domier, L. L. 2002. Genetic analysis of scab resistance QTL in wheat with microsatellite and AFLP markers. Genome 45:719-727.

41. Zhou, W. C., Kolb, F. L., Yu, J., Bai, G.., Larry, L., and Domier, L. L. 2004. Molecular characterization of Fusarium head blight resistance in Wangshuibai with simple sequence repeat and amplified fragment length polymorphism markers. Genome 47:1137-1143. 